\title{
Analysis of Variance Applied to Blood Glucose Values for Assessing Insulin Preparations and State of Lability in Diabetes
}

\author{
L.P. Hedner and $\AA$. Nordín \\ Department of Medicine, University Hospital, Lund, Sweden \\ Received: January 8, 1968
}

\begin{abstract}
Summary. A method for numerical evaluation of the quality of blood glucose control in diabetes mellitus is presented. Blood glucose values were obtained $4-9$ times daily during periods of 5 days. By analysis of variance estimates were obtained for 1. Blood glucose variations during the day, used as a parameter for assessment of the efficiency of a given insulin preparation in an individual patient, and also for comparison of different insulin preparations in a group of patients. - 2. The variation of the mean blood glucose levels from day to day, influenced a.o. by the lability of the diabetes. - 3. The constancy of the pattern of the blood glucose curves during different days, influenced by the lability of the disease. The two latter factors were combined to give a parameter which under controlled conditions may be used for classification of the lability of diabetes. - The method is exemplified by application to different types of diabetes disease and treatment. Four insulin preparations were compared in a group of patients. A change of insulin in several cases caused fairly great changes in the parameter measuring the efficiency of the insulin preparation. The parameter measuring lability of diabetes showed a characteristic level for each patient, with only small changes throughout the experimental periods. - In our experienee, the present method has proved to be useful and has the advantage of being derived from a well defined statistical analysis.
\end{abstract}

Analyse de variance appliquée aux waleurs de la glycémie pour évaluer les préparations d'insuline et le degré de labilité dans le diabète

Résumé. On décrit une méthode pour l'évaluation numérique de la qualité de la régulation de la glycémie dans le diabète sucré. La glycémie a été déterminée 4-9 fois pendant la journée durant des périodes de 5 jours. Au moyen de l'analyse de variance on a fait les estimations suivantes: 1 . Les variations de la glyeémie pendant la journée, employées comme paramètre pour l'évaluation de l'efficacité d'une préparation donnée d'insuline chez le même individu et pour la comparaison de différentes préparations d'insuline dans un groupe de malades. 2. Les variations de la glycémie moyenne d'un jour à l'autre sous l'influence entre autre de la labilité du diabète. - 3. Les courbes glycémiques à des jours différents, influencées par la labilité du diabète. Les facteurs numéro 2 et 3 ont été combinés pour obtenir un paramètre qui, sous des conditions définies, peut être employé pour la classification de la labilité du diabète. Cette méthode a été appliquée à différents types de diabète et de traitement.
On a comparé 4 préparations d'insuline dans un groupe de malades. On a trouvé que le changement de préparation d'insuline causait dans plusieurs cas des modifications considérables dans le paramètre qui mesure l'efficacité de la préparation d'insuline. Le paramètre qui mesure la labílité du diabète montra un niveau caractéristique pour chaque malade avec seulement de faibles changements pendant tout le temps d'expérimentation. - Selon notre expérience, il s'agit d'une méthode utile et qui a l'avantage d'être dérivée d'une analyse statistíque bien défnie.

Anwendung der Varianzanalyse auf Blutzuckerwerte zur Beurteilung von Insulinpröparaten und des Ausmaßes der Staffwechselschavankungen bei Diabetes

Zusammenfassung. Es wird über eine Methode für die numerische Beurteilung der Qualität der Blutzuckerkontrolle beim Diabetes mellitus berichtet. Die Blutzuckerwerte wurden 4-9 mal täglich während Perioden von jeweils 5 Tagen bestimmt. Mittels Varianzanalyse wurden folgende Kriterien bewertet: 1. Blutzuckervariationen während des Tages als Parameter für die Effektivität eines bestimmten Insulinpräparates bei ein und demselben Patienten sowie fïr den Vergleich verschiedener Insulinpräparate innerhalb einer Gruppe von Patienten. - 2. Die Schwankungen des durchschnittlichen Blutzuckergehaltes von Tag zu Tag, in Abhängigkeit u. a. von der Diabeteslabilität. - 3. Die GleichmäBigkeit des Bildes der Blutzuckerkurve an verschiedenen Tagen, ebenfalls in Ab. hängigkeit von der Diabeteslabilität. Die beiden letztgenannten Faktoren wurden ebenfalls miteinander kombiniert in der Absicht, einen Parameter zu erhalten, der unter kontrollierten Bedingungen für die Klassifizierung der Diabetslabilität herangezogen werden könnte. - Die Methode wird am Beispiel verschiedener Diabetestypen und Behandlungen erläutert. Vier Insulinpräparate wurden an ein und derselben Gruppe von Patienten verglichen. Ein Wechsel des Insulinpräparates verursachte in mehreren Fällen recht erhebliche Veränderungen des die Effektivität des Präparates messenden Parameters, wogegen der die Labilität des Diabetes messende Parameter ein für jeden einzelnen Patienten charakteristisches und während der Versuchsdauer sich lediglich geringfügig änderndes Bild zeigte. - Nach unserer Erfahrung hat sich diese Methode als wertvoll erwiesen und hat den Vorteil aus einer wohldefinierten statistischen Analyse hergeleitet zu sein.

Key-words: Control of diabetes mellitus, insulin.
Several methods have been devised to find a numerical value for the quality of blood glucose control in the treatment of diabetes mellitus. Such techniques are wanted for an objective evaluation of therapeutic results, and in clinical trials of insulin preparations. Izzo and CRUMr [3] compared different types of insulin on the basis of the blood glucose variation, which was separated into one intra-daily and one inter-daily component. Jersild [4] assessed the quality of blood glucose control by calculating how large a percentage of the blood glucose values were in the range $75-$ $200 \mathrm{mg}$ per $100 \mathrm{ml}$. Recently, SchLICHTKRULL et al. [6] 
presented the M-value as a quantitative index of the lack of efficiency of the treatment in the diabetic patient. By using a modified logarithmic scale, low blood glucose values close to hypoglycaemia were given increased weight. The range $105-140 \mathrm{mg}$ per $100 \mathrm{ml}$ was regarded as optimal. The final evaluation of the results by this method was judged by the agreement with a subjective assessment of the curves by a group of experienced clinicians. This and other methods measure the lack of efficiency of insulin treatment rather than analyzing the causes of it, and they do not take the normal blood glucose variation into account.

For a detailed evaluation of the results in diabetes therapy it was thought preferable to treat separately the different factors influencing it. We wanted numerical expressions for the effect of the insulin preparations, the instability of the disease and the regularity in the observations from which these factors were calculated. In the present paper we report our experiences with an analysis of variance applied to blood glucose values collected from patients with diabetes mellitus and also from some of the same patients during periods with different types of treatment.

\section{Material and Methods}

The present studies were carried out in 35 subjects with diabetes mellitus. Five of them had no therapy other than diet, ten were treated orally with sulphonyl- containing about $1700 \mathrm{kcal}$ daily, with small variations from day to day $(<10 \%)$ of caloric content and distribution between protein $(100-110 \mathrm{~g})$, fat $(60-65 \mathrm{~g})$ and carbohydrate (155-160 $\mathrm{g}$ daily). The breakfast contained about $370 \mathrm{kcal}$, the lunch about $580 \mathrm{kcal}$ and the dinner about $470 \mathrm{kcal}$; extra meals given at 10,15 and $20 \mathrm{~h}$ contributed about $290 \mathrm{kcal}$ all together.

Blood glucose determinations in the non-diabetic subjects were made 9 times during one day, the time points being identical with those in Table 1 . The patients treated with diet only, and those treated with oral preparations, were followed for 5 days with 4 daily blood glucose determinations at $8^{00}, 12^{00}, 15^{00}$ and $19^{00} \mathrm{~h}$. Out of 20 insulin-treated patients, five were followed with 9 daily blood glucose determinations during four periods consisting of 5 days each. These patients were subjectively selected to represent different degrees of instability of the disease. During each new period, a different insulin preparation was used, but the dose remained unchanged. For each new insulin preparation two days was allowed before starting the study. The four insulin preparations used consisted of rapid, medium and slow acting insulin, mixed in different proportions ${ }^{1}$. They were marked I, II, III and IV. The remaining fifteen insulin-treated patients were followed with 4 daily observations during one or more 5-day periods.

Blood glucose determinations were performed according to the glucose oxidase method of Marks [5]. Two technicians were especially delegated to take the

Table 1. Analysis of variance of blood glucose values ( $\mathrm{mg}$ per $100 \mathrm{ml}$ ) obtained 9 times daily during a 5 day period in a patient treated with insulin. Mean values from non-diabetic subjeats have been subtracted as described in text

\begin{tabular}{lrrrrrrrrrrr}
\hline $\begin{array}{l}\text { Time } \\
\text { Day }\end{array}$ & $8^{30}$ & $9^{30}$ & $\mathbf{1 0}^{\mathbf{3 0}}$ & $\mathbf{1 2 ^ { 0 0 }}$ & $\mathbf{1 3}^{00}$ & $14^{30}$ & $16^{30}$ & $18^{00}$ & $19^{00}$ & Sum \\
\hline 1 & 142 & 155 & 135 & 106 & 79 & 65 & 99 & 143 & 129 & 1053 \\
2 & 126 & 102 & 154 & 158 & 145 & 119 & 151 & 105 & 121 & 1181 \\
3 & 118 & 164 & 170 & 143 & 116 & 105 & 133 & 127 & 140 & 1216 & 863 \\
4 & 111 & 153 & 162 & 128 & 45 & 84 & 56 & 42 & 82 & 1028 \\
5 & 93 & 122 & 154 & 138 & 96 & 93 & 110 & 104 & 118 & 102 \\
\hline Sum & 590 & 696 & 775 & 673 & 481 & 466 & 549 & 521 & 590 & 5341 \\
\hline
\end{tabular}

\begin{tabular}{|c|c|c|c|c|c|c|c|}
\hline Source of variance & $\begin{array}{l}\text { Sum of } \\
\text { squares }\end{array}$ & $\begin{array}{l}\text { Degrees of } \\
\text { freedom }\end{array}$ & $\begin{array}{l}\text { Mean } \\
\text { square }\end{array}$ & $F$ & $P$ & $\begin{array}{l}\text { Expected mean } \\
\text { square }\end{array}$ & Varianco \\
\hline Between columns & 17189 & 8 & 2149 & 3.84 & $<0.01$ & $\sigma_{e}^{2}+5 \sigma^{2} C$ & 318 \\
\hline Between rows & 8725 & 4 & 2181 & 3.89 & $>0.01<0.05$ & $\sigma^{2} e+9 \sigma^{2}{ }_{R}$ & 180 \\
\hline Residual & 17918 & 32 & 560 & & & $\sigma^{2} e$ & 560 \\
\hline Combined & 26643 & 36 & 740 & & & $\sigma^{2}{ }_{e}+\sigma^{2} \mathrm{R}$ & 740 \\
\hline Total & 43832 & 44 & & & & & \\
\hline
\end{tabular}

urea preparations, and 20 with insulin. Ten non-diabetic subjects with normal values for fasting blood glucose and no glucosuria were included for investigation of the normal blood glucose variation over the day.

During the experiments, all subjects were on a diet samples and perform the analyses. About 2000 blood glucose determinations were performed. den. 


\section{Treatment of Data}

For precise and objective evaluation of the blood glucose values numerical expressions were desirable which permitted statistical treatment. The blood glucose values from each patient were therefore treated according to a method for analysis of variance [7]. The critical property of an insulin preparation should be its ability to keep a low blood glucose variation over the day and night. The rest of the blood glucose variation was not regarded to be regularly influenced by the effect of the insulin preparation used. The values were arranged and treated as exemplified in Table 1.

The meaning of the terms appearing in Table 1 may be described as follows:

The mean squares obtained in the analysis of variance express the total variation "Between columns" and "Between rows" respectively. However, the mean square is generally considered to be the linear sum of two factors, namely the residual variance $\left(\sigma^{2} e\right)$ and the "Between columns" $\left(\sigma^{2} C\right)$ (or "Between rows", $\sigma^{2}{ }^{2}$ ) variance, the latter giving the columns (or row) effect. The calculation of mean squares and variances appear in the table. The significance of the variance is calculated by the $F$-test. When the residual variance exceeded the "Between columns" or the "Between rows" mean square, the corresponding variance was denoted by zero.

The analysis of variance appearing in Table 1 was applied to the problem of separately expressing the effect of insulin and the effect of the disease in the following way:

Between columns (mean square and variance) gives that part of the total variation which is caused by differences between the column-sums of blood glucose values. Each column represents a certain time for sampling during the day (Table 1). If these differences are small, the mean square and the variance will be low. With greater differences between the sums of columns the mean square will rise, indicating an unsatisfactory therapeutic result. In the latter case the cause of the high mean square may then be elucidated by calculating the variance, and by examination of its significance by the $\mathrm{F}$-test. If the variance is significant, an unsuitable insulin preparation or schedule of administration should be suspected. If the high mean square is combined with a low or insignificant variance, the patient may have a labile diabetes (causing a high residual variance), and no improvement of the therapeutic result should be expected by changing the insulin preparation. Thus, with the approach used here, the mean square may serve as one expression for the therapeutio result where the role of the insulin preparation is indicated by calculating the variance. It should be noted that only the variations, but not the absolute level of the blood glucose values, influence these parameters. Therefore, judgement of the therapeutic result must also include the mean blood glucose level for the whole experimental period, which adds information about the adequacy of the dosage of insulin.
Physiologically there is a certain postprandial variation, which was assessed by following the blood glucose level in a group of non-diabetic subjects on the fixed diet and calculating the mean values at each time point (Fig. 1). In the diabetic the blood glucose variation should be estimated, not in relation to a fixed basic level, but to the normally occurring variation of blood glucose. Therefore, in patients followed with 9 observations daily, the normal mean values were subtracted from the observed values before the analysis of variance. Thus, when the diabetic patient is optimally controlled, his blood glucose curve closely follows the normally occurring variation, which is then corrected for, giving a low "Between columns" mean square.

Between rows mean square gives that part of the total variation that is caused by different mean blood glucose levels during different days. If this level remains comparatively unchanged from day to day the "Between rows" mean square will attain a low value. A patient with changing levels has a higher value.

The "Between rows" value may be influenced by factors not considered part of the disease pattern, such as daily variations in the absorption of the injected insulin, in degree of muscular activity and in amount of food consumed. One kind of lability of the disease may theoretically be described by the variation remaining when these exogenous factors are under control. In practice, the effect of exogenous factors can never be completely eliminated. Therefore, under controlled conditions, we made the approximation to ascribe the whole "Between rows" variance and mean square to the lability of the disease.

The residual variance is an expression for the constancy of the blood glucose pattern. If a patient reveals the same pattern of blood glucose variation each day, the residual variance will be low. This will apply whether the "Between columns" mean square is low or high, or the "Between rows" mean square is low or high. When new insulin preparations are screened in clinical trials, diabetic patients showing low and stable "Residual" variances should be preferred for testing. Results obtained in patients with high or changing "Residual" variances should be rejected.

"Between rows" and "Residual" variances were both considered to be influenced by the lability of the diabetes, and both of them should be considered in classification of the lability. For this purpose we suggest:

The combined variance, which is a combination of the "Between rows" and the "Residual" variances. It is obtained by addition of the sums of squares for these two factors, divided by the sum of their degrees of freedom.

It is evident that patients revealing great and irregular blood glucose variations, leading to a high "Combined" variance, will subjectively be judged to be labile, but this does not necessarily mean that the "Combined" variance exclusively measures the whole 
lability of the disease. The relationship between the "Combined" variance and the lability of the disease is difficult to settle as no reliable objective estimate for the true lability is known.

Comparison of variances and mean squares. It is essential that the mean squares to be compared are derived from systems with the same number of daily observations and the same number of days. Namely, if the number of daily observations is increased, the "Between rows" mean square will rise, and if the number of days is increased, the "Between columns" mean square will rise. The corresponding variances are, however, not influenced by the number of observations to the same extent, but may be influenced by the time points selected for additional or omitted observations.

If a patient shows a higher "Between columns" variance during a period with one insulin preparation. but a lower one with another preparation during the next period, the latter preparation seems to be superior. However, the variances and mean squares represent noncentral $\chi^{2}$ distributions, and therefore no simple statistical test can be directly applied in comparing them. One indirect method may be to investigate, via the F-test, whether the "Between columns" variance is significant or not, but a non-significant "Between columns" variance with one preparation does not mean a statistically significant superiority compared with a preparation giving a significant "Between columns" variance.

The comparison of "Between columns" values in a group of patients is perhaps irrational since the group may consist of patients whose individual differences require different types of insulin preparations in the individual cases. Thus it may be said a prion, that it is almost impossible to denominate a certain insulin preparation as the best one in general. If, however, such a comparison is to be made, the method may be that of Friedman's two-sided analysis of variance with rank numbers [1].

\section{Results}

1. Non-diabetic subjects, The mean blood glucose values in 10 non-diabetic subjects are shown in Fig. 1. These mean values were subtracted from the observed values before the analysis of variance in cases of diabetes where 9 daily blood glucose values were taken. The values at 8 and $12 \mathrm{~h}$ are very similar, those at $14^{30}$ and $19 \mathrm{~h}$ slightly higher. Thus, the values to be subtracted at these time points are so similar that the effect of a subtraction on the "Between columns" mean square may be negligible. Therefore, subtraction was omitted in cases where 4 daily blood glucose values were taken at $8,12,15$ and $19 \mathrm{~h}$.

The blood glucose variation shown in Fig. 1 corresponds to a "Between columns" variance of 183. In this case, the "Between rows" variance refers to differences between subjects, and is thus not to be compared with the "Between rows" variance used below. The "Residual" variance was 127. The figures given here and in the following refer to blood glucose values in $\mathrm{mg}$ per $100 \mathrm{ml}$ as the basis for the analysis of variance.

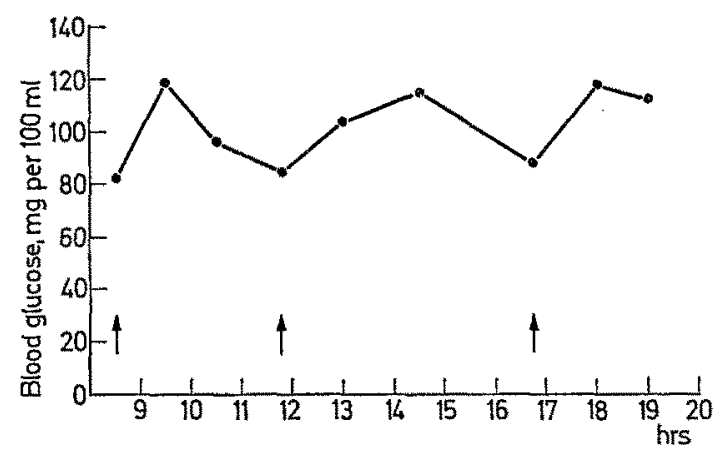

Fig. 1. Postprandial changes of mean blood glucose values in 10 non-diabetic subjects on the fixed diet used for all patients in the investigation. The meals are indicated with arrows. The mean standard deviation was $11.3 \mathrm{mg}$ per $100 \mathrm{ml}$

2. Diabetic patients, treated with diet only (5 patients). Four blood glucose values daily during 5 days were obtained in each patient. The "Between columns" mean squares ranged from 100 to 1625 , the variances from 0 to 120 , none of them significant at $P<0.05$. The "Between rows" mean squares ranged from 150 to 1034 , the variances from 0 to 202 , none of them significant. The "Residual" variances ranged from 50 to 406 , and the "Combined" variances from 75 to 427 .

3. Orally-treated diabetic patients (10 patients). Four blood samples per day were taken during a period of 5 days. One period is exemplified in Figure $2 \mathrm{~A}$. The "Between columns" mean squares ranged from 500 to 5246 , the variances from 0 to 694,4 of them significant at $P<0.05$. The "Between rows" mean squares ranged from 104 to 4384 , the variances from 0 to 833 , significant in two cases. The "Residual" variances ranged from 180 to 1523 , and the "Combined" variances from 189 to 2341 .

4. Diabetic patients, treated with insulin. a) Four observations per day: the periods comprised 5 days throughout. In this material, all mean squares and variances ranged from very low to very high values in different combinations. In our experience, patients whose blood glucose variation during the day was subjectively judged to be acceptable, revealed "Between columns" mean squares below 1000. Fair control comprised values up to 5000 and bad control above 5000 . The lowest value recorded was 102 , the highest was 173464. For further comparisons, see Figure 2, which shows daily blood glucose curves together with mean squares and variances from patients representing different degrees of blood glucose control.

In Table 2 there seems to be a general resemblance between the magnitude of the "Between columns" and "Between rows" variances. This is, however, not a constant phenomenon when the total material is con- 
sidered, and the combination of a high "Between columns" variance with a low "Between rows" or "Combined" variance was present in several cases (e.g. Fig. 2), suggesting that a change of insulin preparation might result in a better therapeutic result. This was also verified in a few cases. blood glucose level. a) Within patients: Each of the five patients in the insulin trial experiment was followed for four weeks. Depending on insulin treatment several of the patients revealed relatively great changes, espe. cially in the "Between colvuns" mean squares and variances. Changes in "Between columns" and "Be-

Table 2. Variances and mean squares in five patients during comparative evaluation of fout insultin preparations $(I-I V)$. The figures for each preparation and patient are based on 45 blood giveose determinations obtained during 5 days.

$\mathrm{BC}$ stands for "Between columns", BR for "Between rows"

\begin{tabular}{|c|c|c|c|c|c|}
\hline \multirow[t]{2}{*}{ Patient } & \multirow[t]{2}{*}{ Variation } & \multicolumn{4}{|c|}{ Insulin preparation } \\
\hline & & $\mathrm{I}$ & II & III & IV \\
\hline M. G. & $\begin{array}{l}\mathrm{BC} \text { mean square } \\
\mathrm{BC} \text { variance }\end{array}$ & $\begin{array}{l}2168 \\
310^{\mathrm{a}}\end{array}$ & $\begin{array}{r}2640 \\
470^{\mathrm{a}}\end{array}$ & $\begin{array}{r}2280 \\
392^{a}\end{array}$ & $\begin{array}{r}276 \\
0\end{array}$ \\
\hline Man & $\begin{array}{l}\text { BR mean square } \\
\text { BR variance }\end{array}$ & $\begin{array}{r}262 \\
0\end{array}$ & $\begin{array}{l}1450 \\
129^{\mathrm{a}}\end{array}$ & $\begin{array}{l}2012 \\
188^{\mathrm{a}}\end{array}$ & $\begin{array}{r}809 \\
50\end{array}$ \\
\hline 48 years & $\begin{array}{l}\text { Residual variance } \\
\text { Combined variance }\end{array}$ & $\begin{array}{l}620 \\
581\end{array}$ & $\begin{array}{l}290 \\
419\end{array}$ & $\begin{array}{l}321 \\
509\end{array}$ & $\begin{array}{l}462 \\
512\end{array}$ \\
\hline J.J. & $\begin{array}{l}\text { BC mean square } \\
\text { BC variance }\end{array}$ & $\begin{array}{l}4264 \\
752^{\mathrm{a}}\end{array}$ & $\begin{array}{l}5504 \\
948^{\mathrm{a}}\end{array}$ & $\begin{array}{l}2149 \\
318^{a}\end{array}$ & $\begin{array}{c}2089 \\
306^{\mathrm{a}}\end{array}$ \\
\hline Man & $\begin{array}{l}\text { BR mean square } \\
\text { BR variance }\end{array}$ & $\begin{array}{r}1308 \\
89\end{array}$ & $\begin{array}{r}894 \\
15\end{array}$ & $\begin{array}{r}2181 \\
180\end{array}$ & $\begin{array}{r}191 \\
0\end{array}$ \\
\hline 74 years & $\begin{array}{l}\text { Residual variance } \\
\text { Combined variance }\end{array}$ & $\begin{array}{l}504 \\
503\end{array}$ & $\begin{array}{l}762 \\
777\end{array}$ & $\begin{array}{l}560 \\
740\end{array}$ & $\begin{array}{l}557 \\
505\end{array}$ \\
\hline C. R. & $\begin{array}{l}\text { BO mean square } \\
\text { BO variance }\end{array}$ & $\begin{array}{l}5153 \\
875^{a}\end{array}$ & $\begin{array}{l}5513 \\
964^{\mathrm{a}}\end{array}$ & $\begin{array}{l}7322 \\
1641^{\mathrm{a}}\end{array}$ & $\begin{array}{l}3940 \\
541^{\mathrm{a}}\end{array}$ \\
\hline Max & $\begin{array}{l}\text { BR mean square } \\
\text { BR variance }\end{array}$ & $\begin{array}{r}1936 \\
128\end{array}$ & $\begin{array}{r}1673 \\
109\end{array}$ & $\begin{array}{r}4164 \\
379^{a}\end{array}$ & $\begin{array}{r}872 \\
0\end{array}$ \\
\hline 68 years & $\begin{array}{l}\text { Residual variance } \\
\text { Combined variance }\end{array}$ & $\begin{array}{l}780 \\
908\end{array}$ & $\begin{array}{l}695 \\
804\end{array}$ & $\begin{array}{r}756 \\
1135\end{array}$ & $\begin{array}{l}1234 \\
1182\end{array}$ \\
\hline D. P. & $\begin{array}{l}\mathrm{BC} \text { mean square } \\
\mathrm{BC} \text { variance }\end{array}$ & $\begin{array}{r}22756 \\
3280^{a}\end{array}$ & $\begin{array}{l}65434 \\
12508^{\mathrm{a}}\end{array}$ & $\begin{array}{l}57620 \\
10931\end{array}$ & $\begin{array}{r}1548 \\
0\end{array}$ \\
\hline Woman & $\begin{array}{l}\text { BR mean square } \\
\text { BR variance }\end{array}$ & $\begin{array}{c}29591 \\
2582^{\mathrm{a}}\end{array}$ & $\begin{array}{r}6069 \\
353\end{array}$ & $\begin{array}{r}9413 \\
717\end{array}$ & $\begin{array}{r}11036 \\
1100\end{array}$ \\
\hline 50 years & $\begin{array}{l}\text { Residual variance } \\
\text { Combined variance }\end{array}$ & $\begin{array}{l}6355 \\
8937\end{array}$ & $\begin{array}{l}2896 \\
3249\end{array}$ & $\begin{array}{l}2963 \\
3680\end{array}$ & $\begin{array}{l}3333 \\
4433\end{array}$ \\
\hline F.N. & $\begin{array}{l}\mathrm{BC} \text { mean square } \\
\mathrm{BC} \text { variance }\end{array}$ & $\begin{array}{c}145242 \\
28763^{a}\end{array}$ & $\begin{array}{c}165144 \\
32206^{a}\end{array}$ & $\begin{array}{l}131604 \\
25211^{2}\end{array}$ & $\begin{array}{r}3666 \\
377\end{array}$ \\
\hline Man. & $\begin{array}{l}\text { BR mean square } \\
\text { BR variance }\end{array}$ & $\begin{array}{r}512 \\
0\end{array}$ & $\begin{array}{c}26334 \\
2469^{a}\end{array}$ & $\begin{array}{r}53912 \\
5374^{\mathrm{a}}\end{array}$ & $\begin{array}{r}36295 \\
4931^{a}\end{array}$ \\
\hline 55 years & $\begin{array}{l}\text { Residual variance } \\
\text { Combined variance }\end{array}$ & $\begin{array}{l}1427 \\
1325\end{array}$ & $\begin{array}{l}4112 \\
6581\end{array}$ & $\begin{array}{r}5550 \\
10924\end{array}$ & $\begin{array}{r}1779 \\
6710\end{array}$ \\
\hline
\end{tabular}

a Indicates a significant variance $(P<0.01)$.

b) Nine observations daily: In the five patients controlled with 9 observations daily, the experiment was designed as a comparison between four insulin preparations, designated I-IV, each of them given to the patients for a period of 5 days. The mean squares and variances obtained appear in Table 2.

In all cases the lowest "Between columns" variance was obtained with preparation IV. If the group were to be treated as an entity, the comparison of the "Between columns" variances may be done according to the analysis of variance with rank numbers [1] indicating a significant $(P<0.001)$ difference between the preparations in the group.

5. Correlation between variances. Influence from mean tween rows" mean squares and "Residual" variances were, however, not correlated to each others, nor to mean blood glucose values.

b) Between patients: Differences in "Between columns" and "Between rows" mean squares and variances were frequently observed to go in the same direction. It is apparent that the connection is far from. absolute, and in several cases high mean squares or variances occurred combined with low ones as exemplified in Fig. 2. However, when the whole insulintreated material ( 4 observations daily) is considered, a formal calculation of the correlation between the "Between rows" and the "Between columns" mean squares resulted in a correlation coefficient of +0.39 . 
The corresponding value for the correlation between the mean blood glucose value for each experimental period and the "Between columns" mean square was +0.34 .

\section{Discussion}

The aim of the present study was to express the effect of insulin preparations and the lability of the disease in figures, based on a statistically valid method. The analysis of variance was selected to determine separately the variations of blood glucose level which were considered to be of interest. We considered the criterion of a well suited insulin preparation to be its ability to keep the blood glucose variation as low as possible during the $24 \mathrm{~h}$ period between the injections. Because meals and periods of physical exercise under controlled conditions were also repeated with $24 \mathrm{~h}$ intervals, it was natural to perform the analysis of variance according to the variation within and between $24 \mathrm{~h}$ periods as exemplified in Table 1 . The blood glucose values were considered to be represented by the normal distribution closely enough to justify the use of the analysis of variance outlined above (which is rather insensitive to moderate deviations from the normal distribution). It should be mentioned here that the selection of the time points for sampling is not at random, making the term "variance" used here not corresponding to variance in a strictly statistical meaning. However, the method of calculation is the same, so this expression has still been used to avoid confusion.

With this approach the "Between columns" mean square and variance may be used for assessment of the lability. However, if certain uncontrollable exogenous factors by definition are included in the lability, the "Combined" variance may rather be used as a substitute for the imprecise definitions inherent in the terms
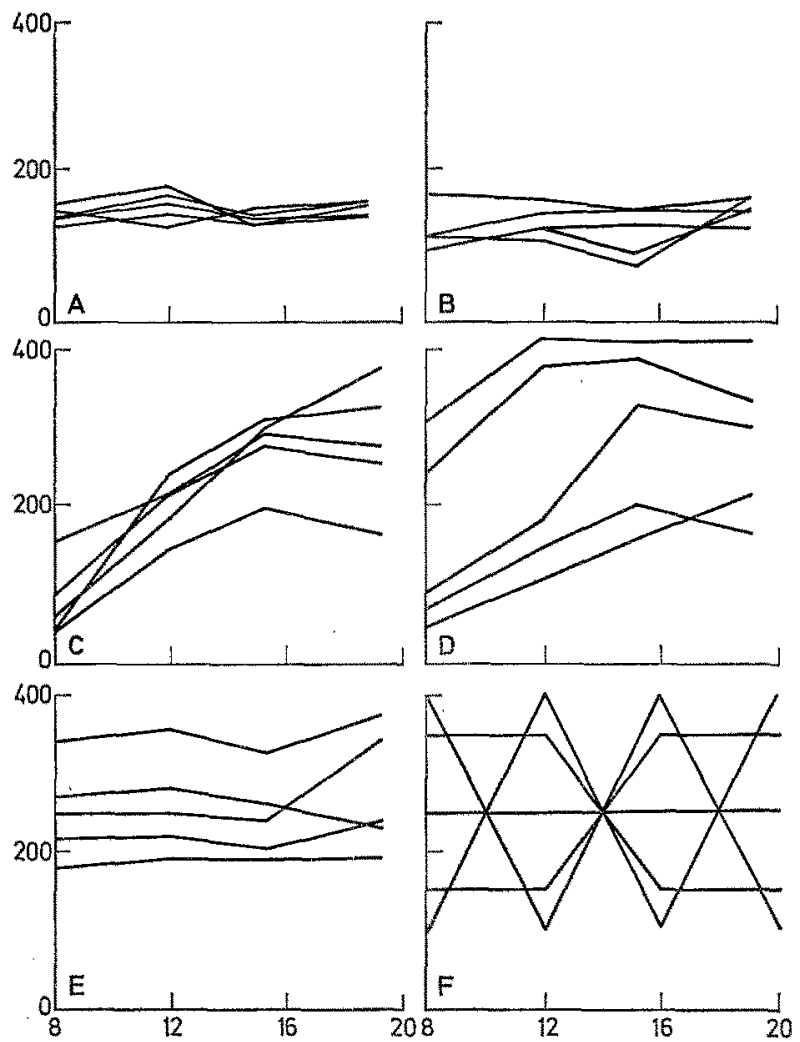

Fig. 2. Blood glucose in $\mathrm{mg}$ per $100 \mathrm{ml}$ (ordinate) related to time (abscissa) during 5 day periods, exemplifying different combinations of mean squares and variances in 5 female diabetic patients and 1 constructed case

\begin{tabular}{|c|c|c|c|c|c|c|c|c|c|}
\hline \multirow[b]{2}{*}{ Figure } & \multirow[b]{2}{*}{ Patient } & \multirow[b]{2}{*}{ Age, years } & \multirow[b]{2}{*}{ Therapy } & \multicolumn{2}{|c|}{ Between columns } & \multicolumn{2}{|c|}{ Between rows } & \multirow{2}{*}{$\begin{array}{l}\text { Residual } \\
\text { variance }\end{array}$} & \multirow{2}{*}{$\begin{array}{l}\text { Combined } \\
\text { variance }\end{array}$} \\
\hline & & & & $\begin{array}{l}\text { mean } \\
\text { square }\end{array}$ & variance & $\begin{array}{l}\text { mean } \\
\text { square }\end{array}$ & variance & & \\
\hline A & H. A. & 86 & Oral & 546 & 66 & 104 & 0 & 218 & 189 \\
\hline$B$ & R. S. & 68 & Insulin & 867 & 107 & 1850 & $379^{a}$ & $\mathbf{3 3 3}$ & 712 \\
\hline $\mathrm{C}$ & H. T. & 73 & Insulin & 48097 & $9415^{\mathrm{a}}$ & 6842 & $1455^{\mathrm{a}}$ & 1022 & 2477 \\
\hline $\mathbf{D}$ & E. D. & 63 & Insulin & 30400 & $5800^{a}$ & 59100 & $14420^{\circ}$ & 1392 & 15812 \\
\hline $\mathbf{E}$ & S. J. & 56 & Insulin & 733 & 50 & 13407 & $3252^{\mathrm{a}}$ & 401 & 3653 \\
\hline $\mathbf{F}$ & \multicolumn{3}{|c|}{ Constructed case } & 0 & 0 & 0 & 0 & 21600 & 16300 \\
\hline
\end{tabular}

a indicates a significant variance $(P<0.01)$

ability of the insulin preparation to maintain an even blood glucose level between the injections, i.e. how good it suits the patient's individual requirement of insulin during the day. The rest of the variation of the blood glucose values, expressed by the "Combined" variance, will react with a high value in a patient with great and irregular variations of blood glucose values, which is generally subjectively judged to be a labile type of diabetes. However, since no objective and reliable measure of the true lability to our knowledge exists, it is impossible to investigate whether the "Combined" variance exclusively measures the whole labile and stable diabetes. A consequence, then, must be that the separation into one parameter for the suitability of the insulin preparation and another for the lability of the disease is not absolute, as e.g. a change of insulin preparation may lead to a changed reproducibility of the absorption of the injected insulin, and thus also influence the "Combined" variance. Such limitations will, however, apply to any method based on blood glucose values, and if this is kept in mind, the information from estimates obtained by the present method may be useful.

The present method, like other methods based on 
blood glucose values during a certain period, gives an instantaneous picture of the situation during that very period. When repeated under the same conditions, certain differences in the estimates should be expected. The "Combined" variances in Table 2, which were not expected to be much influenced by the change of insulin preparations, show only moderate changes within patients during the four experimental periods with the exception of subject F.N. With insulin preparation I, he had a considerably lower "Combined" variance than otherwise found in this patient with similar preparations. We think that the low "Combined" variance was not due to the insulin preparation, but rather that the very lability in patients with high "Combined" variances may be labile so that a low value can occur by chance. It is difficult to reach a representative value for such a lability unless the number of days in each experimental period is considerably increased. This patient was included here to illustrate this phenomenon, but otherwise values from such a patient should be rejected in a trial of insulin.

In this material, 4 daily blood glucose controls were used in some cases, and 9 in others. Of course the variances determined will reach a greater accuracy with an increasing number of observations. However, the number of daily observations must often be limited for practical reasons, but the magnitude of the "Between columns" mean square should not be influenced by mean squares on this basis. We found that these estimates differed only to a minor degree from the original ones. The deviations were not systematic. Thus the reduction of the number of observations during the period of the day covered seemed to be of small significance for the magnitude of the "Between columns" mean squares. The present experiments were performed to illustrate the method rather than the patients or the insulin preparations. However, when the aim is to characterize the latter, the blood glucose values should cover the whole $24 \mathrm{~h}$ period and values during the night thus should be included.

Izzo and CRUMP [3] used the same basic principle as we have done; that is, they separated the blood glucose variation during the day from the day-to-day variation. However, there are differences in the method of calculation. Their inter-daily variation corresponds to our "Between rows" mean square. Their intra-daily variation includes the residual variance, and corresponds to the "Within rows" variance in an one-sided analysis of variance. Different types of insulin were compared depending on their effect on these two variations in a material of patients, divided subjectively into one stable and one instable group. By calculating mean squares and variances the present method might be expected to give a more distinct picture of the effects of the insulin preparation and of the disease, respectively. We think that the residual variance should be

Table 3. Comparative evaluation of four insulin preparations by the present method of analysis of variance and by determination of the $M$-value in five patients

\begin{tabular}{|c|c|c|c|c|c|c|}
\hline \multirow[t]{2}{*}{ Patient } & \multirow[t]{2}{*}{ Parameter } & & \multicolumn{4}{|c|}{ Insulin preparation } \\
\hline & & & $\overline{\mathrm{I}}$ & II & III & IV \\
\hline & Between & mean & 2168 & 2640 & 2280 & 276 \\
\hline \multirow[t]{2}{*}{ M. G. } & $\begin{array}{l}\text { columns } \\
M \text {-value }\end{array}$ & $\begin{array}{l}\text { square } \\
\text { variance }\end{array}$ & $\begin{array}{c}310^{\mathrm{a}} \\
19.3\end{array}$ & $\begin{array}{r}470^{a} \\
12.9\end{array}$ & $\begin{array}{c}392^{\mathrm{a}} \\
16.8\end{array}$ & $\begin{array}{c}0 \\
10.9\end{array}$ \\
\hline & Between & mean & 4264 & 5504 & 2149 & 2089 \\
\hline \multirow[t]{2}{*}{ J. J. } & $\begin{array}{l}\text { columns } \\
M \text {-value }\end{array}$ & $\begin{array}{l}\text { square } \\
\text { variance }\end{array}$ & $\begin{array}{c}752^{\mathrm{a}} \\
10.8\end{array}$ & $\begin{array}{l}948^{a} \\
18.1\end{array}$ & $\begin{array}{c}318^{a} \\
21.4\end{array}$ & $\begin{array}{r}306^{\mathrm{a}} \\
\quad 7.0\end{array}$ \\
\hline & Between & $\begin{array}{l}\text { mean } \\
\text { square }\end{array}$ & 5153 & 5513 & 7322 & 3940 \\
\hline \multirow[t]{2}{*}{ C. R. } & $\begin{array}{l}\text { columns } \\
M \text {-value }\end{array}$ & variance & $\begin{array}{c}875^{\mathrm{a}} \\
10.9 \\
\end{array}$ & $\begin{array}{r}964^{\mathrm{a}} \\
9.3 \\
\end{array}$ & $\begin{array}{r}1641^{\mathrm{a}} \\
10.3 \\
\end{array}$ & $\begin{array}{c}541^{\mathrm{a}} \\
10.1 \\
\end{array}$ \\
\hline & Between & $\begin{array}{l}\text { mean } \\
\text { square }\end{array}$ & 22756 & 65434 & 57620 & 1548 \\
\hline D. P. & $\begin{array}{l}\text { columns } \\
M \text {-value }\end{array}$ & variance & $\begin{array}{r}3280^{\mathrm{a}} \\
57.0\end{array}$ & $\begin{array}{r}12508^{\mathrm{a}} \\
61.8\end{array}$ & $\begin{array}{r}10931^{\mathrm{a}} \\
56.7\end{array}$ & $\begin{array}{c}0 \\
59.2\end{array}$ \\
\hline & Between & $\begin{array}{l}\text { mean } \\
\text { square }\end{array}$ & 145242 & 165144 & 131604 & 3666 \\
\hline & $\begin{array}{l}\text { columns } \\
M \text {-value }\end{array}$ & variance & $\begin{array}{r}28763^{\mathrm{a}} \\
92.8\end{array}$ & $\begin{array}{r}32206^{\mathrm{a}} \\
107.3\end{array}$ & $\begin{array}{c}25211^{\mathrm{a}} \\
145.8\end{array}$ & $\begin{array}{l}377 \\
30.5\end{array}$ \\
\hline
\end{tabular}

a indicates a significant variance $(P<0.01)$.

this, provided that the number of days in each experimental period is kept constant. In cases with 9 daily observations we extracted the values at $8^{30}, 12,14^{30}$ and $19 \mathrm{hrs}$ and recalculated the "Between columns" used rather for selection of patients than included in the parameter used for assessment of the preparations in a trial of insulin.

HaLlas-MörLmR et al. [2] in testing the lente insu- 
lins used three parameters - the mean blood sugar, the differences between the highest and the lowest blood sugar during a $24 \mathrm{~h}$ period, and the dispersion of the individual $24 \mathrm{~h}$ blood glucose curves. JERSIL [4] expressed the degree of control by the percentage of blood glucose determinations falling between 75 and $200 \mathrm{mg}$ per $100 \mathrm{ml}$, and considered a percentage over 80 as a sign of satisfactory control. The use of these methods will be limited, for they do not permit a separation of factors causing inefficient blood glucose control, and they are less sensitive than the present method.

SCHLICHTKRoLL et al. [6] evaluated the efficiency of diabetes therapy by the introduction of the $M$-value. It is obtained from a formula based on blood glucose determinations, and primarily constructed to agree with an empirical ranking of therapeutic results made by nine diabetes experts. The estimates obtained with the present method measure other factors than the $M$ value. With the material from the insulin trial a comparison was made between the present treatment of data and the $M$-value method (Table 3 ). The two methods agree upon the best insulin preparation in most of the cases, the lowest $M$-values agreeing with the lowest "Between columns" mean squares. However, the deflections made by the $M$-value are smaller than those of the "Between columns" mean square, most strikingly seen in subject D.P., where changes in the mean blood glucose level disguise the improvement otherwise obtained with preparation IV. The comparison illustrates the view that the $M$-value is useful as a general index of blood glucose control in patients with diabetes. However, e.g. in testing insulin preparations, the present method may be more efficient, since the effect of the insulin preparation is obtained separately, and not included in a general expression for the quality of blood glucose control.

Judged from the blood glucose curves, insulin preparations I-III appeared to contain an insufficient proportion of long-acting insulin. In subjects M.G., J.J. and C.R. the insulin demand was probably low during the night, and thus their "Between columns" mean squares were only moderately raised. The other two patients presented in Table 2 were of a more labile type, as indicated by higher "Combined" variances. They probably had a considerable requirement of insulin during the night, for when treated with preparations I-III they revealed very high blood glucose values in the morning. There was a gradual decrease to normal or even subnormal values in the evening. The great blood glucose variations observed with the unsuitable preparations led to high "Between columns" mean squares which were remarkably different from those obtainable with a more suitable preparation (IV). Generally, it is more difficult to find a preparation which gives a good blood glucose control in labile diabeties. It is possible that this is the background to the obser- vation that the "Between columns" mean squares were correlated to the "Between rows" mean squares. However, in several cases it was possible to reach a comparatively low "Between columns" mean square in spite of a high "Between rows" or "Combined" variance, and these cases probably caused the correlation coefficient to be as low as 0.39 .

A considerable difference between the lowest and highest blood glucose value during the day was registered in patients with high "Between columns" mean squares. Because the lowest blood glucose values were in the normal range, the mean daily or weekly blood. glucose value must necessarily be considerably elevated. Thus, an increased "Between columns" mean square should invariably be combined with an elevated mean blood glucose value, otherwise some blood glucose values will fall within the hypoglycaemia range. On the other hand, a high mean blood glucose value is not incompatible with a low "Between columns" mean square. We think that this may form an explanation for the weak correlation $(r=+0.34)$ observed between the mean blood glucose values and the "Between columns" mean squares.

The judgement of the general blood glucose control in a given patient by the present method should consider three factors: a) The "Between columns" mean square and variance, which illustrates the adequacy of the insulin preparation and administration schedule; b) The "Combined" variance, which illustrates the role of the lability of the disease; and c) The mean blood glucose value for the experimental period, which should reflect the adequacy of the dose of insulin.

\section{References}

1. Friedman, M.: The use of ranks to avoid the assumption of normality implicit in the analysis of variance. J. Amer. Statist. Ass. 32, 675-683 (1937).

2. Hateas-Mölteer, K., M. Jersitd, K. Pethresen, and J. Schitchtkruli: The Lente insulins. Dan. med. Bull. 1, 132-141 (1954).

3. IzZo, J.L., and S. CRUMP: A clinical comparison of modified insulins. J. clin. Invest. 29, 1514-1527 (1950).

4. JERsiLd, M.: Insulin zine suspension. Lancet 1956 1009-1013.

5. MARKS, V.: An improved glucose oxidase method for determining blood, CSF and urine glucose levels. Clin. chim. Acta 4, 395-400 (1959).

6. SchliohrkRuLI, J., O. MUNCK, and M. Jersild : The M-value, an index of blood sugar control in diabetes. Acta med. scand. 177, 95-102 (1965).

7. Snedecor, G.W.: Statistical methods. 5th ed. p. 327. Ames: Iowa State Univ. Press 1956.

Dr. I. P. HEDNGR

Dr. Å. NoRDÉn

Dept. of Medicine

University Hospital

Lund, Sweden 